\title{
Cancer cell-specific MHCII expression as a determinant of the immune infiltrate organization and function in the non-small cell lung cancer tumor microenvironment
}

Amber M. Johnson ${ }^{1}$, Jennifer M. Boland² ${ }^{\text {, Julia Wrobel }}{ }^{3}$, Emily K. Klezcko Mary Weisner-Evans ${ }^{1}$, Lynn Heasley ${ }^{4}$, Eric T. Clambey ${ }^{5}$, Raphael A. Nemenoff ${ }^{1}$, and Erin L. Schenk ${ }^{1 *}$

${ }^{1}$ Department of Medicine, ${ }^{3}$ Department of Biostatistics, and Informatics, ${ }^{4}$ Department of Anesthesiology, and School of Dental Medicine, University of Colorado Anschutz Medical Campus, Aurora, CO 80045.

2Division of Anatomic Pathology, Department of Laboratory Medicine and Pathology, Mayo Clinic, Rochester, MN 55905

*Corresponding author e-mail: erin.schenk@CUAnschutz.edu

ELS is supported by NIH grant K12 CA086913, ACS IRG \#16-184-56 from the American Cancer Society to the University of Colorado Cancer Center, and a grant from the Cancer League of Colorado. RN is supported by NIH grant CA236222, DOD grant W81XWH1910221, and grants from the Cancer League of Colorado and the LUNGevity foundation.

All authors report no conflict of interest 


\section{$\underline{\text { Abstract }}$}

$\underline{\text { Introduction }}$

In patients with non-small cell lung cancer (NSCLC), the prognostic significance of the tumor

microenvironment (TME) immune composition has been demonstrated using single or dual-marker

staining on sequential tissue sections. While these studies show that relative abundance and localization

of immune cells are important parameters, deeper analyses of the NSCLC TME are necessary to refine

the potential application of these findings to clinical care. Currently, the complex spatial relationships

between cells of the NSCLC TME and potential drivers contributing to its immunologic composition

remain unknown.

Methods

We employed multispectral quantitative imaging on the lung adenocarcinoma TME in 153 patients with

resected tumors. On a single slide per patient, we evaluated the TME with markers for CD3, CD8, CD14,

CD19, major histocompatibility complex II (MHCII), cytokeratin, and DAPI. Image analysis including

tissue segmentation, phenotyping, and spatial localization were performed.

\section{$\underline{\text { Results }}$}

Specimens where $\geq 5 \%$ of lung cancer cells expressed $\mathrm{MHCII}$ (MHCI $\left.{ }^{\mathrm{hi}} \mathrm{TME}\right)$ demonstrated increased

levels of $\mathrm{CD}^{+}$and $\mathrm{CD} 8^{+} \mathrm{T}$ cell and $\mathrm{CD} 14^{+}$cell infiltration. In the MHCII ${ }^{\mathrm{hi}} \mathrm{TME}$, the immune infiltrate was

closer to cancer cells and expressed an activated phenotype. Morphologic image analysis revealed 
cancer cells in the $\mathrm{MHCI}{ }^{\text {hi }} \mathrm{TME}$ more frequently interfaced with $\mathrm{CD} 4^{+}$and $\mathrm{CD} 8^{+} \mathrm{T}$ cells. Patients with an

MHCII hi TME experienced improved overall survival $(p=0.046)$.

\section{$\underline{\text { Conclusions }}$}

Lung cancer cell-specific expression of MHCIl associates with levels of immune cell infiltration, spatial

localization, and activation status within the TME. This suggest cancer cell-specific expression of MHCII

may represent a biomarker for the immune system's recognition and activation against the tumor. 


\section{Introduction}

The tumor microenvironment (TME) is a complex interface between cancer cells, stroma, and

infiltrating immune cells. Multiple preclinical models of cancer have demonstrated that these interactions

shape the natural history of tumor progression including the early events of primary tumor formation and

how rapidly metastases develop(Reviewed in [1]). In patients with lung cancer, multiple analyses have

demonstrated the prognostic significance of the TME immune composition[2]. High levels of immune

infiltration within hematoxylin and eosin stained sections were associated with improved patient outcomes

in a cohort of 1,546 patients with resected non-small cell lung cancer (NSCLC)[3]. Even in patients with

stage I disease, immunologic characteristics of the TME including the proportion of $\mathrm{FoxP}^{+}$cells to total T

cell infiltration correlated with disease recurrence in 956 patients with resected lung adenocarcinoma[4].

In addition to the differences in the numbers of immune cells, the location of specific populations within

the NSCLC TME influences patient outcomes. In a cohort of 797 patients with resected lung cancer, high

numbers of $\mathrm{CD}^{+} \mathrm{T}$ cells in the stroma associated with improved overall survival[5]. While these studies

and others have demonstrated that relative abundance and localization of immune cells within the

NSCLC TME are important parameters, deeper analyses of the NSCLC TME are necessary to refine the

potential application of these findings to clinical care[1]. Currently, the complex spatial relationships

between cells of the NSCLC TME and potential drivers contributing to its immunologic composition

remain unknown. 
Previously, we have reported that cancer cell-specific expression of major histocompatibility complex II (MHCII) modulates the TME within orthotopic mouse models of lung cancer[6].

Downregulation of MHCII in CMT167, a murine lung adenocarcinoma that expresses MHCII in vivo, resulted in fewer $\mathrm{CD} 4^{+}$and $\mathrm{CD} 8^{+} \mathrm{T}$ cells compared to the parental line[6]. Conversely, upregulation of MHCII in LLC, a murine lung adenocarcinoma that does not express MHCII in vivo, led to increased infiltration of $\mathrm{CD}^{+}$and $\mathrm{CD}^{+} \mathrm{T}$ cells compared to the parental line[6]. Ex-vivo experiments demonstrated MHCIl expressing cancer cells presented antigen to $\mathrm{CD}^{+} \mathrm{T}$ cells and resulted in a Th1 phenotype.

Studies of NSCLC tissues have demonstrated tumor cell positivity for MHCII and that cancer cell expression of $\mathrm{MHCll}$ associates with increased $\mathrm{CD}^{+}{ }^{+} \mathrm{T}$ cell TME infiltration[6, 7]. We hypothesized NSCLC cancer cell-specific expression of MHCII would be a determinant of abundance and spatial organization of the immune infiltration within the NSCLC TME. We tested our hypothesis in a cohort of 153 patients with resected NSCLC adenocarcinoma and employed multispectral imaging for a deeper analysis of multiple cell phenotypes and their relative spatial distributions within the NSCLC TME. Here, we report NSCLC cancer cell-specific expression of MHCII results in a more abundant immune infiltration with a significant increase in proximity and interface of both $\mathrm{CD} 4^{+}$and $\mathrm{CD} 8^{+} \mathrm{T}$ cells to cancer cells. Notably, patients with NSCLC cancer cell-specific expression of MHCIl experience improved overall survival. 


\section{Methods}

Patient Studies: Tumor specimens were collected through a protocol approved by the Mayo Clinic

Institutional Review Board and obtained from the Mayo Clinic Lung Cancer Repository. Written informed consent was obtained from all patients in accordance with the Declaration of Helsinki. Patients were identified from the tissue repository that underwent curative surgical resection of lung adenocarcinoma between 2004 and 2007, who had not previously received cancer directed therapy, and had available residual tumor specimens. The electronic medical record was reviewed and pertinent clinical data including age at time of surgery, gender, smoking status, pack years, and last follow up date or date of death was extracted. Patients were staged based on surgical findings using the 7 th edition of the AJCC TNM system for NSCLC[8]. Formalin-fixed paraffin-embedded (FFPE) tissue blocks were sectioned into $5 \mu \mathrm{m}$ slides by the Pathology Research Core (Mayo Clinic, Rochester, MN). Hematoxylin and eosin slides were reviewed by a thoracic pathologist (JMB) to verify the presence of tumor.

Tissue multiplex immunohistochemistry: Slides from FFPE blocks were stained using Opal IHC Multiplex Assay according to manufacturer's protocol (PerkinElmer) as previously described[9]. Briefly, slides were sequentially stained for CD19 (clone BT51E, dilution 1:50, Leica), CD3 (clone LN10, dilution 1:500, Leica), CD14 (clone SP192, dilution 1:100, Abcam), CD8 (clone C8/144B, dilution 1:100, Dako), HLA-DR + DP + DQ (MHCII) (clone CR3/43, dilution 1:250, Abcam), cytokeratin (polyclonal Z0622, dilution 1:250, Dako) and DAPI (Akoya Biosciences) at the Human Immune Monitoring Shared Resource at CU Anschutz Medical Campus. Whole slide scans were acquired using the 10x objective via the Vectra 
imaging system (Perkin Elmer, version 3.0). Three to five regions from each slide containing tumor and stroma were selected utilizing Phenochart (v1.0.12, Perkin Elmer) for high resolution multispectral acquisition on the Vectra system at $20 \mathrm{X}$ magnification. The images were analyzed with inForm software (v2.4.8, Akoya) to unmix adjacent fluorochromes, subtract autofluorescence (Figure 1A), segment the tissue into tumor and stroma regions (Figure 1B), segment the cells into nuclear, cytoplasmic, and membrane compartments (Figure 1C), and to phenotype the cells according to morphology and cell marker expression (Figure 1D).

Data Analysis: inForm output data was analyzed using the R package Akoya Biosciences phenoptrReports to aggregate phenotype counts using count_phenotypes function for each slide and tissue category[10]. Nearest neighbor analysis was performed with the phenoptrReports nearest_neighbor_summary function[10]. The count_touching_cells function from phenoptrReports uses morphological analysis of nuclear and membrane segmentation maps to find touching cells of paired phenotypes[10]. To determine MHCII expression on cancer cells and immune cells, a threshold of membrane MHCII (Opal 690) mean of .05 positivity was determined by DAPI and MHCII single stain controls.

Statistics: All statistical analysis performed was done with R version 4.0.3, R studio, or GraphPad Prism (v9.0.0, GraphPad Software). P values of $p<.05$ were considered significant. 


\section{Results}

\section{Cancer cell-specific MHCII expression associates with increased levels of TME immune infiltration}

We quantified immune cell infiltration and $\mathrm{MHCll}$ expression in surgical resection specimens of patients with lung adenocarcinoma obtained from the Mayo Clinic Lung Cancer Repository. Patients were selected for multispectral imaging if they had no previous history of lung cancer and did not receive cancer directed therapy prior to surgery. Of the 153 patients evaluated $52.9 \%$ were women. Most of the patients were between ages $65-75(75.8 \%)$, had a significant smoking history of 10 pack/years or more (73.2\%), and were predominantly stage I (62\%), specifically IA (41.8\%), based on pathologic staging

(Table 1). Initial quantification of the total number of immune cells within our cohort demonstrated a marked diversity degree and type of immune infiltration within each resection specimen (Supplemental

\section{Figure 1).}

In our previous work, we reported that cancer cell-specific MHC class II expression alters the immune cell composition of the TME in murine models of lung cancer[6]. We therefore quantified the number of cancer cells positive for $\mathrm{MHCll}$ within each patient specimen as the percent of $\mathrm{CK}^{+}$cells coexpressing MHCII (Figure 2A). To further determine the impact of cancer cell expression of MHCII on the TME, we classified tumor specimens as MHCIl high or MHCIl low based on previous work defining an MHCII high cancer cell population as $\geq 5 \%$ of tumor cells positive for MHCII[11, 12]. In our cohort, $63.4 \%$ ( $n=97$ ) of patients were found to have tumors with $\geq 5 \%$ of cancer cells expressing MHCII $\left(\mathrm{MHCII}{ }^{\text {hi }}\right)$ and 
$36.6 \%(n=56)$ had tumors with $<5 \%$ of cancer cells expressing $\mathrm{MHCll}\left(\mathrm{MHCl}{ }^{10}\right)$. Comparison of clinical characteristics between the $\mathrm{MHCI}^{\text {hi }}$ and $\mathrm{MHCI}^{\text {lo }}$ groups demonstrated no differences in patient distribution (Table 2). Differences were noted in the composition of the TME. The TME of MHCIl hi patients contained significantly increased total levels $\mathrm{CD} 4^{+}$and $\mathrm{CD} 8^{+} \mathrm{T}$ cell infiltrating the TME, and we also observed an increase in $\mathrm{CD} 14^{+}$cells compared to the TME of MHCIIlo patients (Figure 2B and 2C). Within the intratumoral compartment, $\mathrm{MHCI}{ }^{\text {hi }}$ tumors contained more $\mathrm{CD} 8^{+} \mathrm{T}$ cells and increased $\mathrm{CD} 14^{+}$ and $\mathrm{CD} 19^{+}$cells (Supplemental Figure 2A). Stromal infiltration of $\mathrm{CD} 4^{+} \mathrm{T}$ cells and $\mathrm{CD} 14^{+}$cells were higher in $\mathrm{MHClI}^{\text {hi }}$ tumors compared to $\mathrm{MHCIl}^{\text {lo }}$ (Supplemental Figure 2B).

\section{Increased spatial proximity between cancer cells and immune cells in the MHCII ${ }^{\text {hi }}$ TME}

The proximity of immune cells to cancer cells within the TME is a critical determinant of

immunologic activity, and we next determined the spatial localization of each cancer cell and immune cell

by generating spatial coordinates for each cell type[1]. Distances between individual tumor cells and the nearest immune cell phenotypes were calculated. Spatial map views highlight the shorter distances between $\mathrm{CK}^{+}$cancer cells and the nearest $\mathrm{CD}^{+} \mathrm{T}$ cell in an $\mathrm{MHCII}{ }^{\mathrm{hi}}$ compared to an $\mathrm{MHCI}{ }^{\text {lo }}$ tumor

(Figure 3A). Spatial analyses revealed an increased proximity of $\mathrm{CD} 4^{+}$and $\mathrm{CD} 8^{+} \mathrm{T}$ cells, $\mathrm{CD} 19^{+}$, and $\mathrm{CD}_{14}^{+}$immune cells to the cancer cells in $\mathrm{MHCII}^{\mathrm{hi}}$ tumors in contrast to $\mathrm{MHCll}^{\mathrm{lo}}$ tumors (Figure 3B). In addition to the differences in cancer cell proximity, immune cells within the TME of MHCII hi tumors more commonly expressed an activated phenotype compared to MHCIIlo tumors[13-15]. Higher levels of cell surface expression of $\mathrm{MHCll}$ on $\mathrm{CD} 4^{+}$and $\mathrm{CD} 8^{+} \mathrm{T}$ cells, $\mathrm{CD} 14^{+}$cells, and $\mathrm{CD} 19^{+}$cells were noted in 
MHCII hi tumors compared to MHCIIlo tumors (Supplemental Figure 3). These differences remained

significant when comparing tissue compartments reflecting an overall increased level in immune cell

activity within the TME of MHCII hi tumors (Supplemental Figure 3).

Ultimately, a successful anti-tumor response by the immune system culminates in $\mathrm{CD}^{+} \mathrm{T}^{-}$cell

recognition of the tumor and within our cohort we assessed this using morphologic analysis of the cell

surface interface between pairs of cells[16]. Within the TME of MHCIlhi tumors, more cancer cells

demonstrated a morphologic interface with $\mathrm{CD}^{+} \mathrm{T}$ cells in contrast to the TME of MHCII' ${ }^{\circ}$ tumors (Figure

4A, Figure 4B). $C D 8^{+} \mathrm{T}$ cells within the TME of MHClI hi tumors were more frequently interfaced with

CD14+ cells, but not $\mathrm{CD}^{+}{ }^{+} \mathrm{T}$ cells or $\mathrm{CD} 19^{+} \mathrm{B}$ cells (Supplemental Figure $4 \mathrm{~A}$ ). Similarly, tumor cells

were more likely to share a surface interface with $\mathrm{CD}^{+} \mathrm{T}$ cells in $\mathrm{MHCl}{ }^{\text {hi }}$ tumors (Figure 4B, Figure 4C).

$\mathrm{CD}^{+} \mathrm{T}$ cells in the TME of MHCII hi tumors were more frequently interfaced with CD14+

$\mathrm{CD}^{+} \mathrm{T}$ cells or $\mathrm{CD} 19^{+} \mathrm{B}$ cells (Supplemental Figure 4B).

\section{MHCII ${ }^{\text {hi }}$ Tumor Status Predicts Survival}

As our analyses demonstrated $\mathrm{MHCI}^{\text {hi }}$ tumors have an increased quantity of total and activated

immune cells and a higher frequency of T cell interfacing with cancer cells, we performed survival

analyses on our patient cohort. Patients with $\mathrm{MHCII}^{\text {hi }}$ tumors experienced improved 5 year overall

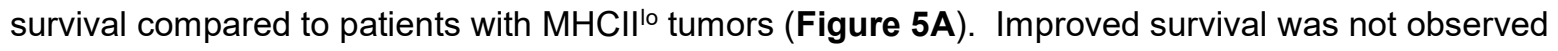

when patients were grouped by high or low levels of immune cell infiltration based on the median of the 
entire cohort (Figure 5B - 5E). In multivariate analysis, cancer cell-specific MHCIl status was predictive of patient outcome (Table 3). Notably, levels of immune cell infiltration, grouped into high or low levels based on the entire cohort average, did not associate with 5 year overall survival.

\section{Discussion}

While the composition of the TME has been recognized as a determinant of cancer progression and response to therapy, most analyses have focused on a limited number of cell types, and not

examined multiple populations and their localization within the tumor. With the application of multispectral tissue imaging and bioinformatic approaches to analyze the TME of resected lung adenocarcinomas, we determined cancer cell MHCIl expression associates with the organization and function of the immune infiltrate within the TME. The TME of MHCII hi tumors contained higher levels of immune cell infiltration, similar to previous observations in melanoma, ovarian, and breast cancers[11, 17, 18]. In contrast to the previous studies of tumor MHCIl expression and immune infiltration by IHC on serial sections, multiparameter tissue imaging allowed for simultaneous determination of multiple cell phenotypes and spatial coordinates in our cohort. With this level of single-cell resolution of phenotype and location, we found an increase in immune cell proximity to the tumor cells and degree of immune cell activation within the TME of MHCII hi tumors. Importantly, within the TME of MHCI/ ${ }^{\text {hi }}$ tumors, cancer cells exhibited more cell surface in interfaces with $\mathrm{CD} 4^{+}$and $\mathrm{CD} 8^{+} \mathrm{T}$ cells, suggesting an increase in $\mathrm{T}$ cell recognition of 
cancer cells. In line with this hypothesis, we found patients with resected lung adenocarcinoma and an

MHCII hi tumor status experienced improved survival.

In part, our data of increased immune cell proximity and interface with cancer cells in MHCII hi

tumors strengthens the connection between improved patient outcomes and mechanistic data from

animal models. In orthotopic models using the murine lung adenocarcinoma CMT-167 that expresses

MHCII in vivo, knockdown of cancer cell-specific MHCIl expression resulted in fewer activated $\mathrm{CD}^{+}{ }^{+}$and

$\mathrm{CD}^{+} \mathrm{T}$ cells within the lung cancer TME[6]. Additionally, knock down of MHCll expression in CMT-167

resulted in larger tumors that were less responsive to therapy[6]. Analogous findings were reported with

the murine lung adenocarcinoma LLC, which does not express MHCII[6, 19]. Animals challenged with

LLC cells transfected to express MHCII showed partial or complete abrogation of tumor growth, which

was dependent on $\mathrm{CD}^{+}$and $\mathrm{CD} 8^{+} \mathrm{T}$ cells[19]. Notably, depletion of classical dendritic cells (CDC) in

transgenic animals with the diphtheria toxin receptor under control of the CD11c promoter, did not impact

the ability of animals to reject MHCII expressing LLC[19]. While other mononuclear phagocytes could

serve as antigen presenting cells (APC) in the absence of $C D C$, one possibility is that the cancer cells

expressing $\mathrm{MHCll}$ present antigen directly to the $\mathrm{CD} 4^{+} \mathrm{T}$ cells, resulting in activation. This in turn would

lead to production of cytokines such as interferon- $\nu$ and augmentation of the immune response in a feed-

forward manner [19]. This potential role of tumor cell as APC was further supported in an animal model

of sarcoma where tumors were not eliminated unless the cancer cell expressed an MHCII neoantigen

[20]. Our observation that cancer cells in $\mathrm{MHClI}^{\text {hi }}$ tumors more frequently interfaced with $\mathrm{CD} 4^{+} \mathrm{T}$ cells 
suggests this cell-cell interaction may play a similar role in immune mediated tumor control in patients with lung cancer.

For patients with clinical and radiographic early stage lung cancer, such as our cohort, the current standard of care is to first proceed with tumor resection[21]. Multiple ongoing clinical trials are evaluating whether neoadjuvant immune checkpoint inhibitors alone or in combination with chemotherapy improves patient outcomes versus standard of care (Reviewed in [22]). Our data associating tumor expression of MHCII with increased immune infiltration and proximity within the TME, indicators of immune recognition of the cancer cells, suggests tumor expression of MHCII may enrich for patients with lung cancer likely to respond to immunotherapy in this setting. Similar observations have been made in other malignancies where tumor expression of MHCII correlates with response to immunotherapy. Patients with metastatic melanoma who received PD-1 or PD-L1 immunotherapy experienced prolonged progression free and overall survival if $\geq 5 \%$ of tumor cells expressed MHCII[11]. Tumor cell expression of MHCIl was also a key differentiator for progression free survival in patients with Hodgkin lymphoma who received PD-1 immunotherapy at least 1 year out from autologous stem cell therapy[23]. For patients with HER2 negative breast cancer, response to PD-1 immunotherapy associated with tumor expression of MHCII[24].

Our study provides translational rationale for evaluating cancer cell-specific expression of MHCII as a biomarker for immunotherapy responsiveness in patients with lung cancer. With our findings, several limitations exist that require the analyses of more modern cohorts. Initial studies can delineate 
whether cancer cell-specific MHCII associates with improved outcomes for patients with metastatic lung cancer receiving immunotherapy alone or in combination with chemotherapy in squamous and nonsquamous histologies. Unlike the neoadjuvant setting, the use of immunotherapy in metastatic lung cancer for first line therapy has been standard of care for several years[21]. With this larger pool of potential patient specimens, further studies can be done with more complex multispectral tissue imaging in conjunction with tissue sequencing to better identify phenotypes and activation status of lymphocytes and leukocytes within the TME. Further work with modern patient cohorts could provide a more detailed insight into the role of cancer cell-specific MHCII and responsiveness to standard of care adjuvant chemotherapy than our cohort was able to address. An extension of our findings would be the hypothesis that patients with MHCII ${ }^{\mathrm{hi}}$ NSCLC possess an active anti-tumor response and adjuvant chemotherapy would not improve survival, akin to observations in patients with deficient mismatch repair colorectal cancer[25]. Standard of care therapy for resected NSCLC continues to evolve and recently the presence of targetable driver oncogenes are now informing adjuvant therapy approaches[26]. While the role of the immune system in targeted therapy responsiveness is unknown, preclinical and translational data suggest engagement of the immune system promotes disease control[9, 27]. Whether cancer cell-specific expression of $\mathrm{MHCll}$ is a determinant of the TME and outcomes in patients with targetable oncogenes is unknown and remains an active area of investigation. In summary, we report that lung cancer expression of $\mathrm{MHCll}$ associates with levels of immune cell infiltration, spatial localization, and activation status within the TME. Along with pre-clinical data, our results suggest lung cancer expression of MHCII 
may serve as a biomarker for the immune system's recognition and activation against the tumor. These

insights may inform future approaches to predicting patient responsiveness to immunotherapy.

\section{Acknowledgements}

ELS is supported by NIH grant K12 CA086913, ACS IRG \#16-184-56 from the American Cancer Society to the University of Colorado Cancer Center, and a grant from the Cancer League of Colorado. RN is supported by NIH grant CA236222, DOD grant W81XWH1910221, and grants from the Cancer League of Colorado and the LUNGevity foundation.

The authors wish to thank the Pathology Research Core at Mayo Clinic for their assistance with specimen preparation. The authors wish to thank the Human Immunology Monitoring Shared Resource at the University of Colorado for their assistance with Vectra panel design and multispectral image acquisition, supported by the Cancer Center Support Grant (P30CA046934) 


\section{$\underline{\text { References }}$}

1. Binnewies, M., et al., Understanding the tumor immune microenvironment (TIME) for effective therapy. Nat Med, 2018. 24(5): p. 541-550.

2. Remark, R., et al., The non-small cell lung cancer immune contexture. A major determinant of tumor characteristics and patient outcome. Am J Respir Crit Care Med, 2015. 191(4): p. 377-90.

3. Brambilla, E., et al., Prognostic Effect of Tumor Lymphocytic Infiltration in Resectable Non-SmallCell Lung Cancer. Journal of Clinical Oncology, 2016. 34(11): p. 1223-1230.

4. Suzuki, K., et al., Clinical Impact of Immune Microenvironment in Stage I Lung Adenocarcinoma: Tumor Interleukin-12 Receptor 62 (IL-12R62), IL-7R, and Stromal FoxP3/CD3 Ratio Are Independent Predictors of Recurrence. Journal of Clinical Oncology, 2012. 31(4): p. 490-498.

5. Donnem, T., et al., Stromal CD8<sup $>+</$ sup $>$ T-cell Density-A Promising Supplement to TNM Staging in Non-Small Cell Lung Cancer. Clinical Cancer Research, 2015. 21(11): p. 2635-2643.

6. Johnson, A.M., et al., Cancer Cell-Intrinsic Expression of MHC Class II Regulates the Immune Microenvironment and Response to Anti-PD-1 Therapy in Lung Adenocarcinoma. J Immunol, 2020. 204(8): p. 2295-2307.

7. He, Y., et al., MHC class I/ expression in lung cancer. Lung Cancer, 2017. 112: p. 75-80.

8. Goldstraw, P., et al., The IASLC Lung Cancer Staging Project: proposals for the revision of the TNM stage groupings in the forthcoming (seventh) edition of the TNM Classification of malignant tumours. J Thorac Oncol, 2007. 2(8): p. 706-14.

9. Maynard, A., et al., Therapy-Induced Evolution of Human Lung Cancer Revealed by Single-Cell RNA Sequencing. Cell, 2020. 182(5): p. 1232-1251 e22.

10. Johnson, K.S. phenoptr: inForm Helper Functions. R package version 0.2.9. 2020; Available from: https://akoyabio.github.io/phenoptr/.

11. Johnson, D.B., et al., Melanoma-specific MHC-Il expression represents a tumour-autonomous phenotype and predicts response to anti-PD-1/PD-L1 therapy. Nat Commun, 2016. 7: p. 10582.

12. Johnson, D.B., et al., Tumor-specific MHC-Il expression drives a unique pattern of resistance to immunotherapy via LAG-3/FCRL6 engagement. JCI Insight, 2018. 3(24).

13. Oshima, S. and D.D. Eckels, Selective signal transduction through the CD3 or CD2 complex is required for class II MHC expression by human T cells. J Immunol, 1990. 145(12): p. 4018-25.

14. Lankar, D., et al., Dynamics of major histocompatibility complex class // compartments during $B$ cell receptor-mediated cell activation. J Exp Med, 2002. 195(4): p. 461-72.

15. Gordon, S., Alternative activation of macrophages. Nature Reviews Immunology, 2003. 3(1): p. 23-35.

16. Fooksman, D.R., et al., Functional anatomy of $T$ cell activation and synapse formation. Annu Rev Immunol, 2010. 28: p. 79-105.

17. Callahan, M.J., et al., Increased HLA-DMB expression in the tumor epithelium is associated with increased CTL infiltration and improved prognosis in advanced-stage serous ovarian cancer. Clin Cancer Res, 2008. 14(23): p. 7667-73.

18. Park, I.A., et al., Expression of the MHC class II in triple-negative breast cancer is associated with tumor-infiltrating lymphocytes and interferon signaling. PLoS One, 2017. 12(8): p. e0182786.

19. Bou Nasser Eddine, F., et al., CIITA-driven MHC class II expressing tumor cells can efficiently prime naive $\mathrm{CD} 4(+) \mathrm{TH}$ cells in vivo and vaccinate the host against parental MHC-II-negative tumor cells. Oncoimmunology, 2017. 6(1): p. e1261777.

20. Alspach, E., et al., MHC-II neoantigens shape tumour immunity and response to immunotherapy. Nature, 2019. 574(7780): p. 696-701. 
21. National Comprehensive Cancer Network. Non-Small Cell Lung Cancer (Version 1.2021).

December 15, 2020]; Available from:

https://www.nccn.org/professionals/physician gls/pdf/nscl.pdf.

22. Gentzler, R.D., D.O. Riley, and L.W. Martin, Striving toward Improved Outcomes for Surgically Resectable Non-Small Cell Lung Cancer: the Promise and Challenges of Neoadjuvant Immunotherapy. Current Oncology Reports, 2020. 22(11): p. 109.

23. Roemer, M.G.M., et al., Major Histocompatibility Complex Class II and Programmed Death Ligand 1 Expression Predict Outcome After Programmed Death 1 Blockade in Classic Hodgkin Lymphoma. Journal of Clinical Oncology, 2018. 36(10): p. 942-950.

24. Wulfkuhle, J.D., et al., Quantitative MHC II protein expression levels in tumor epithelium to predict response to the PD1 inhibitor pembrolizumab in the I-SPY 2 Trial. Journal of Clinical Oncology, 2019. 37(15_suppl): p. 2631-2631.

25. Sargent, D.J., et al., Defective Mismatch Repair As a Predictive Marker for Lack of Efficacy of Fluorouracil-Based Adjuvant Therapy in Colon Cancer. Journal of Clinical Oncology, 2010. 28(20): p. 3219-3226.

26. Wu, Y.-L., et al., Osimertinib in Resected EGFR-Mutated Non-Small-Cell Lung Cancer. New England Journal of Medicine, 2020. 383(18): p. 1711-1723.

27. Gong, K., et al., EGFR inhibition triggers an adaptive response by co-opting antiviral signaling pathways in lung cancer. Nature Cancer, 2020. 1(4): p. 394-409. 


\section{Figure Legends:}

Figure 1: Representative images generated by inForm analysis. A) Spectrally unmixed composite image: pan-cytokeratin (CK) (magenta), CD3 (green), CD8 (red), CD14 (turquoise), CD19 (orange), MHCII (yellow), and DAPI (blue). B) Tissue segmentation map of tumor (red), and stroma (green) regions.

C) Cell segmentation map: nucleus (green) and membrane (outlined in red). D) Phenotype map of $\mathrm{CK}^{+}$ cancer cells (magenta), $\mathrm{CD}^{+}\left(\mathrm{CD} 3^{+} \mathrm{CD} 8^{-}\right) \mathrm{T}$ cells (green), $\mathrm{CD} 8^{+} \mathrm{T}$ cells (red), $\mathrm{CD} 14^{+}$cells (turquoise), CD19+ $B$ cells (orange).

Figure 2: Immune infiltration is increased within the TME of $\mathrm{MHClI}^{\text {hi }}$ tumors. A) Representative images of single stain $\mathrm{CK}$ and $\mathrm{MHCll}$ and the merged image. B) Representative multispectral images of an $\mathrm{MHCI}^{\mathrm{hi}}$ or an $\mathrm{MHCII}^{\mathrm{lo}} \mathrm{TME}$. C) Percent of immune cells present within the TME of each patient by tumor MHCII status. Unpaired t-test. ${ }^{*} p<.05,{ }^{* *} p<.01,{ }^{* * *} p<.001$, NS not significant.

Figure 3: Increased spatial proximity of cancer cells to immune cells within the MHCII ${ }^{\text {hi }} \mathrm{TME}$. A) Representative spatial map image of the distance of nearest $\mathrm{CD} 4^{+}$cell (green) to $\mathrm{CK}^{+}$cell (pink) in an MHCII hi tumor or an $\mathrm{MHCII}^{\text {lo }}$ tumor. B) Average minimum distance of $\mathrm{CK}^{+}$cells to $\mathrm{CD} 14^{+}, \mathrm{CD} 19^{+}, \mathrm{CD}^{+}$, and $\mathrm{CD}^{+}$cells in $\mathrm{MHCI}{ }^{\mathrm{hi}}$ and MHCIIlo cohorts ( $\mathrm{n}=153$, Unpaired T-test, $\left.{ }^{* *} \mathrm{p}<.01,{ }^{* * *} \mathrm{p}<.001\right)$

Figure 4: Cell-cell interface between cancer cells and T cells is more frequent in the MHCII ${ }^{\text {hi }}$ TME.

A) Representative images of cell interface analysis between cancer cells and $\mathrm{CD} 8^{+} \mathrm{T}$ cells in an $\mathrm{MHCll}{ }^{\mathrm{hi}}$ and $\mathrm{MHCII}{ }^{\circ}$ tumor. B) Percent of cancer cells with a cell surface interface with $\mathrm{CD} 4{ }^{+}$or $\mathrm{CD} 8{ }^{+} \mathrm{T}$ cells 
based on tumor MHC status, unpaired t-test, ${ }^{*} p<.05,{ }^{* *} p<.01$. C) Representative images of cell interface analysis between cancer cells and $\mathrm{CD}^{+} \mathrm{T}$ cells in an $\mathrm{MHCl}$ hi or an $\mathrm{MHCll}$ lo tumor.

Figure 5: Five year overall. Stratified by A) Cancer cell-specific MHCIl status, and levels of TME

immune infiltration based on the cohort median of total B) $\mathrm{CD}^{+}$, C) $\mathrm{CD}^{+}$, D) $\mathrm{CD} 14^{+}$, or E) $\mathrm{CD} 19^{+}$cells.

\section{Supplemental Figure Legends}

Supplemental Figure 1: Immune infiltrate profiles of 153 lung adenocarcinoma specimens. Heat map rows represent individual patients and percent of each immune cell type out of total cells in the TME.

Supplemental Figure 2: Proportion of Immune cells within the tissue compartments of the TME.

A) Tumor, B) Stroma. ${ }^{*} p<.05$, unpaired t-test

Supplemental Figure 3: Immune cells within the MHCII ${ }^{\text {hi }}$ TME express higher levels of the

activation marker MHCII. Differences in levels of immune cell expression of MHCII in the TME and stroma and tumor tissue compartments for A) $\mathrm{CD}^{+}$, B) $\mathrm{CD}^{+}$, C) $\mathrm{CD} 14^{+}$, and D) $\mathrm{CD} 19^{+}$cells. Unpaired T-test, $\left.{ }^{* *} p<.01,{ }^{* * *} p<.001\right)$

Supplemental Figure 4: Cell-cell surface interface between T cells and other immune cells within

the $\mathrm{MHCII}^{\mathrm{hi}}$ or the $\mathrm{MHCII}^{\mathrm{Io}}$ TME. Percent of A) CD8 T cells or B) CD4 T cells with morphologic interfaces with CD14, CD19, or other T cells in the MHCII ${ }^{\text {hi }}$ versus MHCII' ${ }^{10}$ ME. Unpaired t-test ${ }^{*} p<.05$ 
Figure 1


$\because 010$ D $\because 090$ $\because-9$ $\because-0$ \%

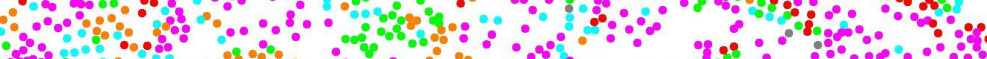

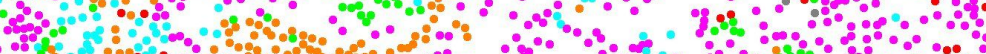
$\therefore$ \% $3 \because-0$

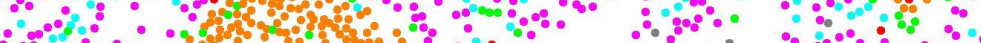

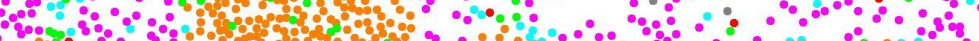

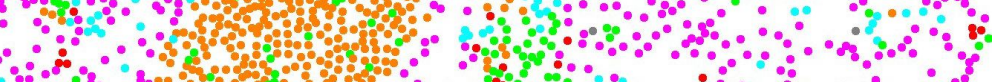
○. 20 \% $\because \because 30$ 8. 
Figure 2

A

\section{CK}

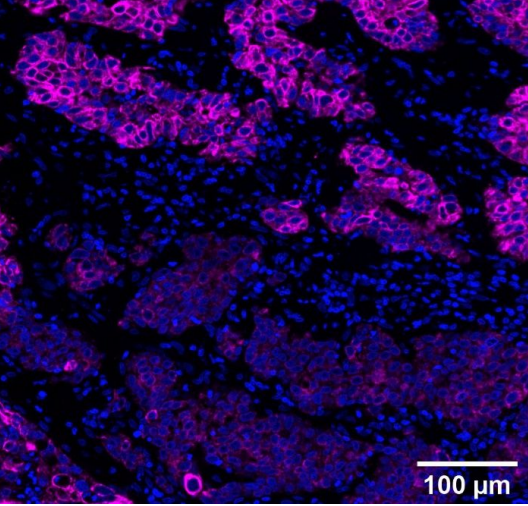

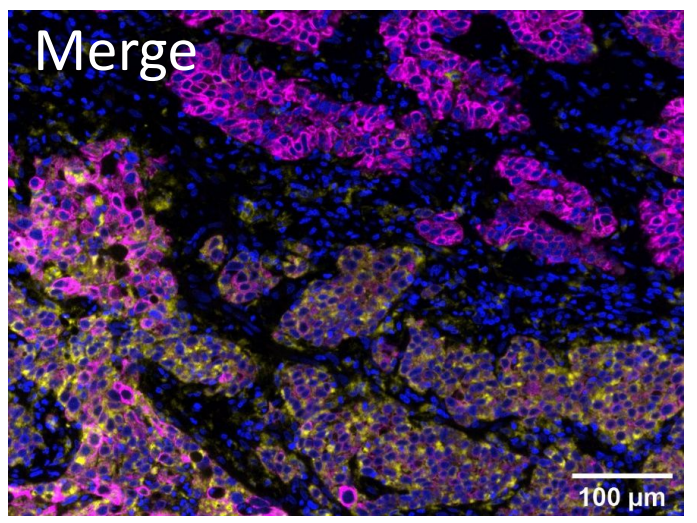

B

\section{MHCI hi}



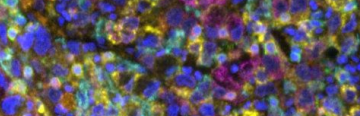

\section{?}

$x^{2}=2,250$
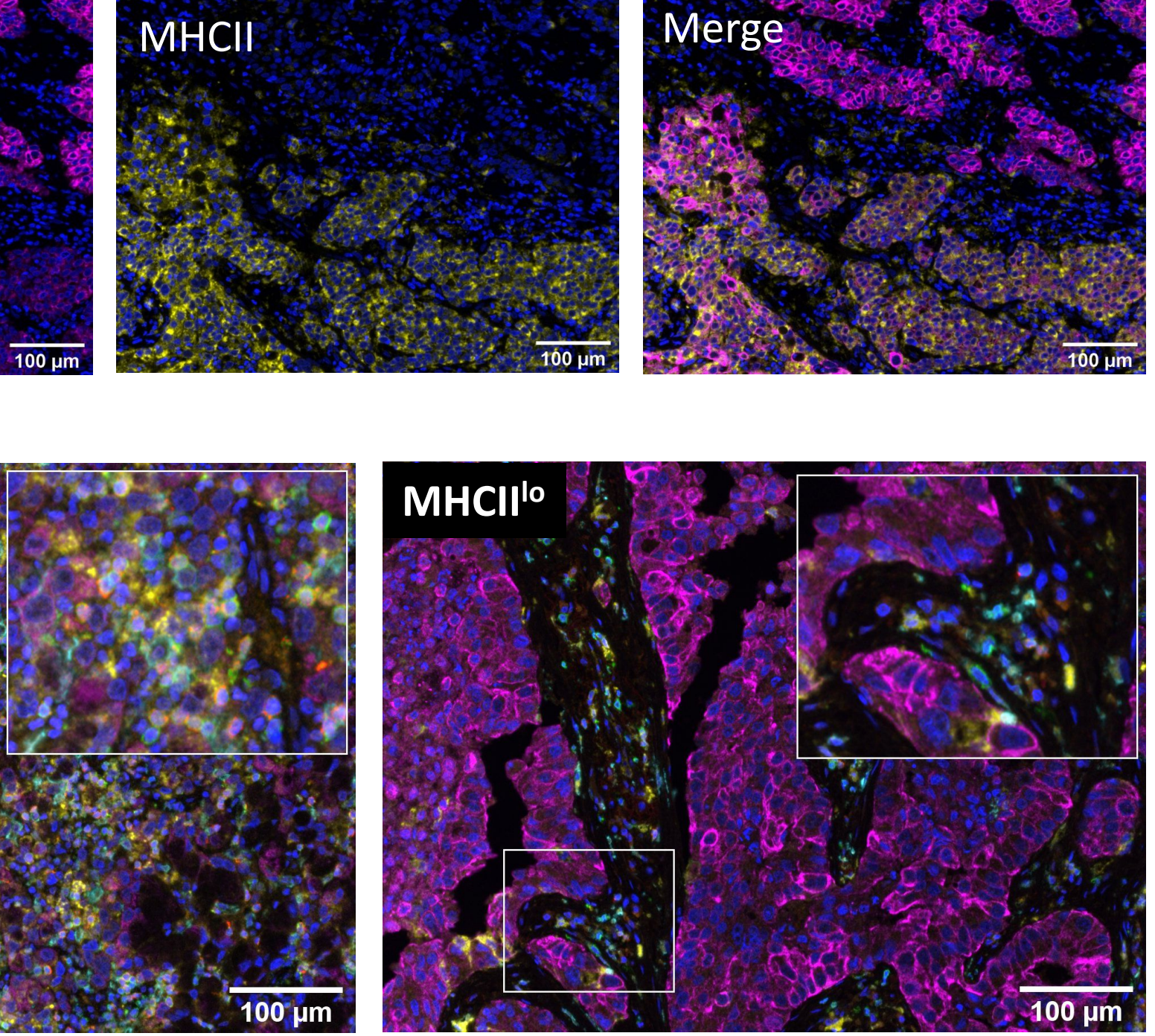

CK MHCII CD4 CD8 CD14 CD19
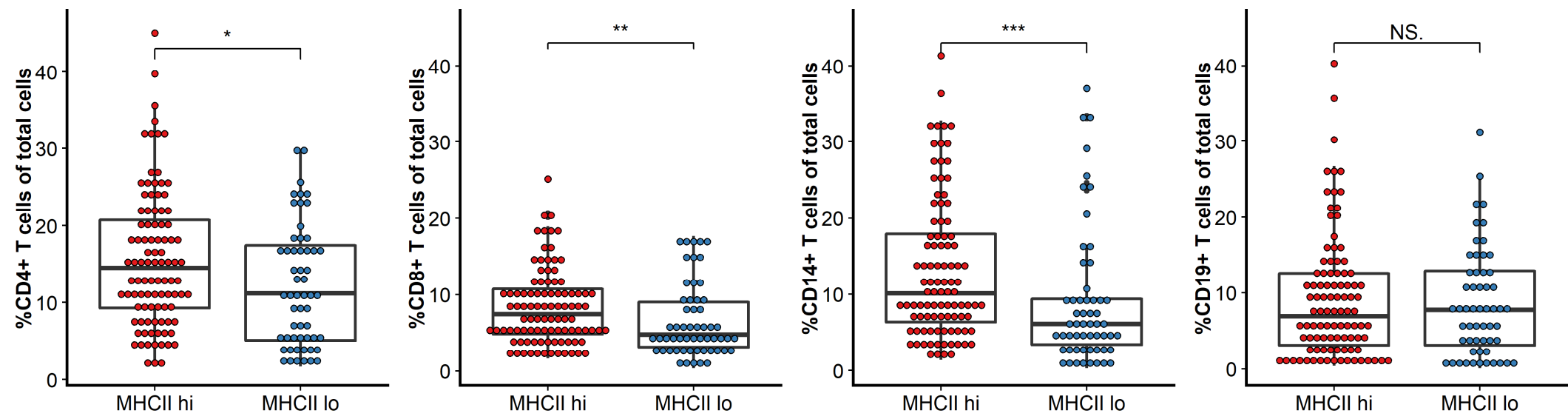
A
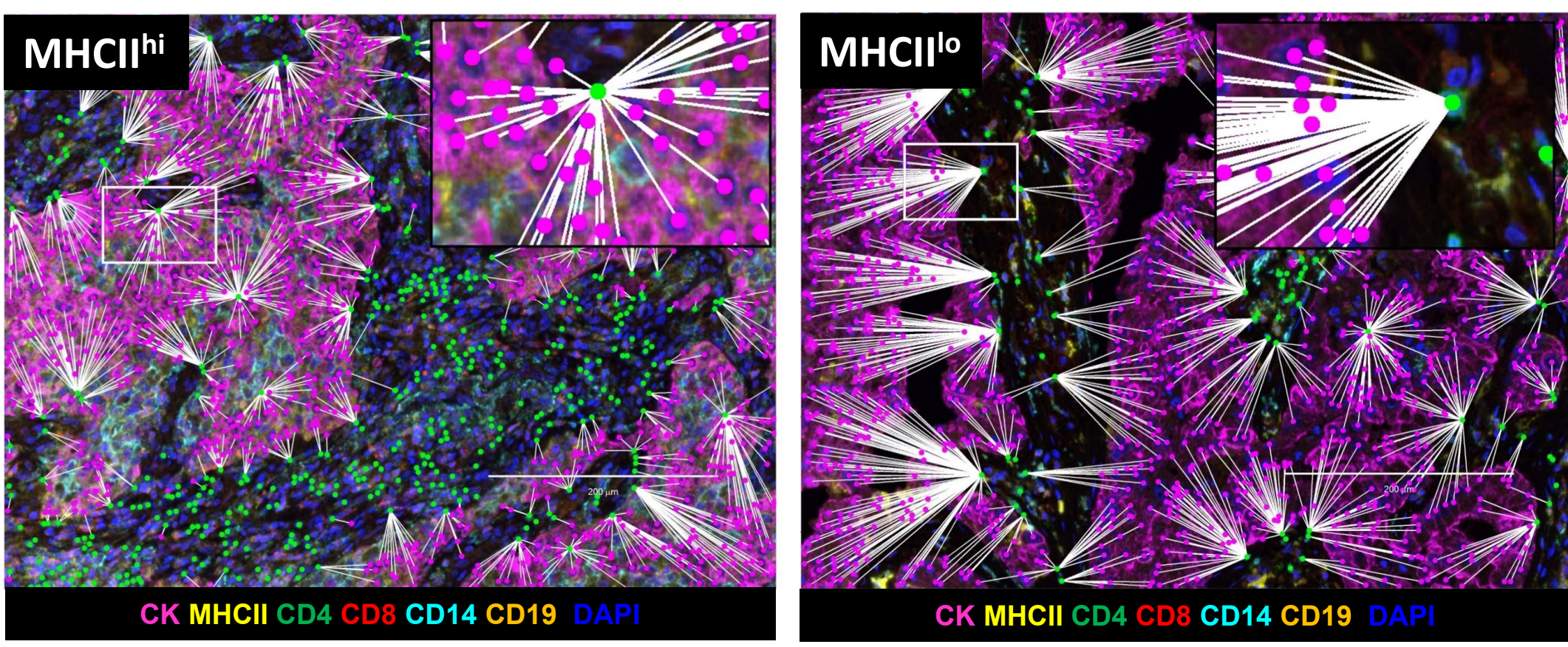

Phenotype CD4+ $\mathrm{CK}+$

B
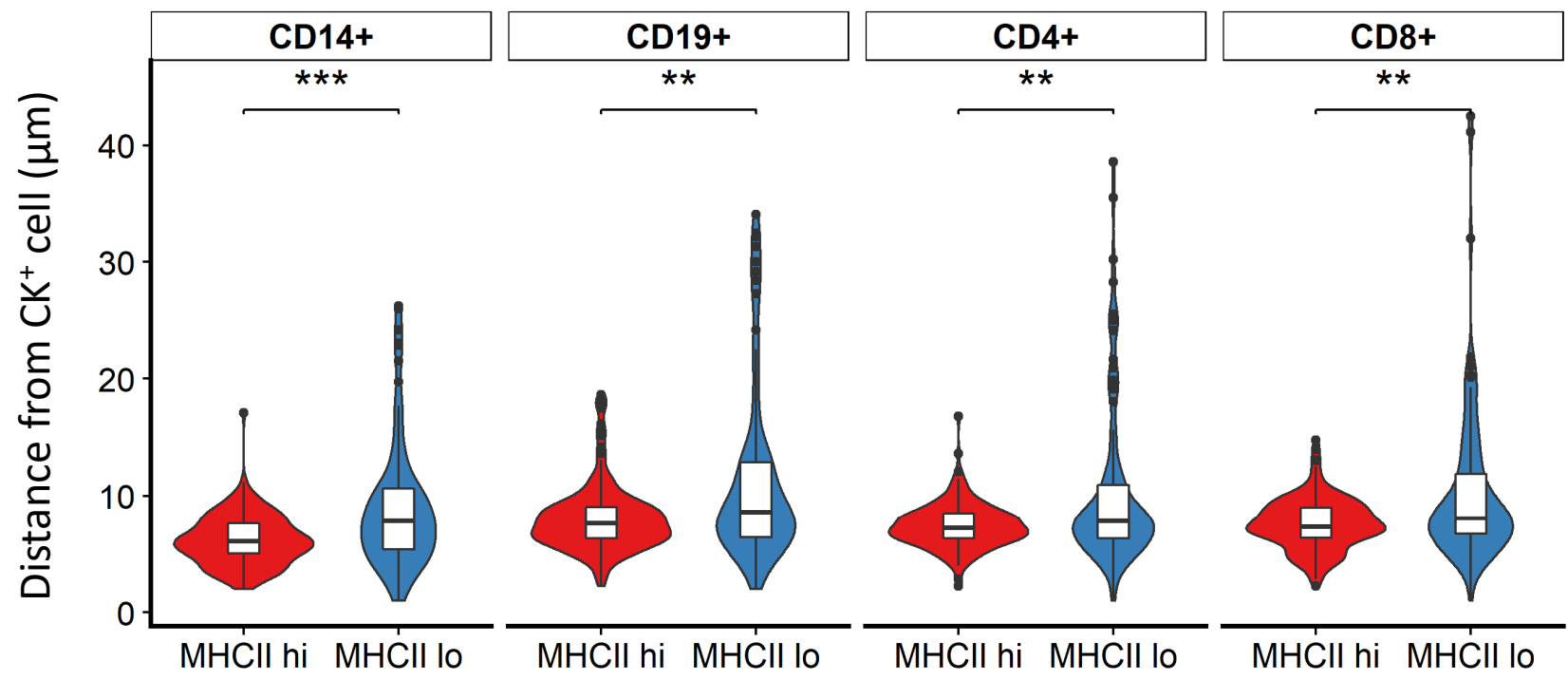

MHCII hi

MHCII lo 
Figure 4
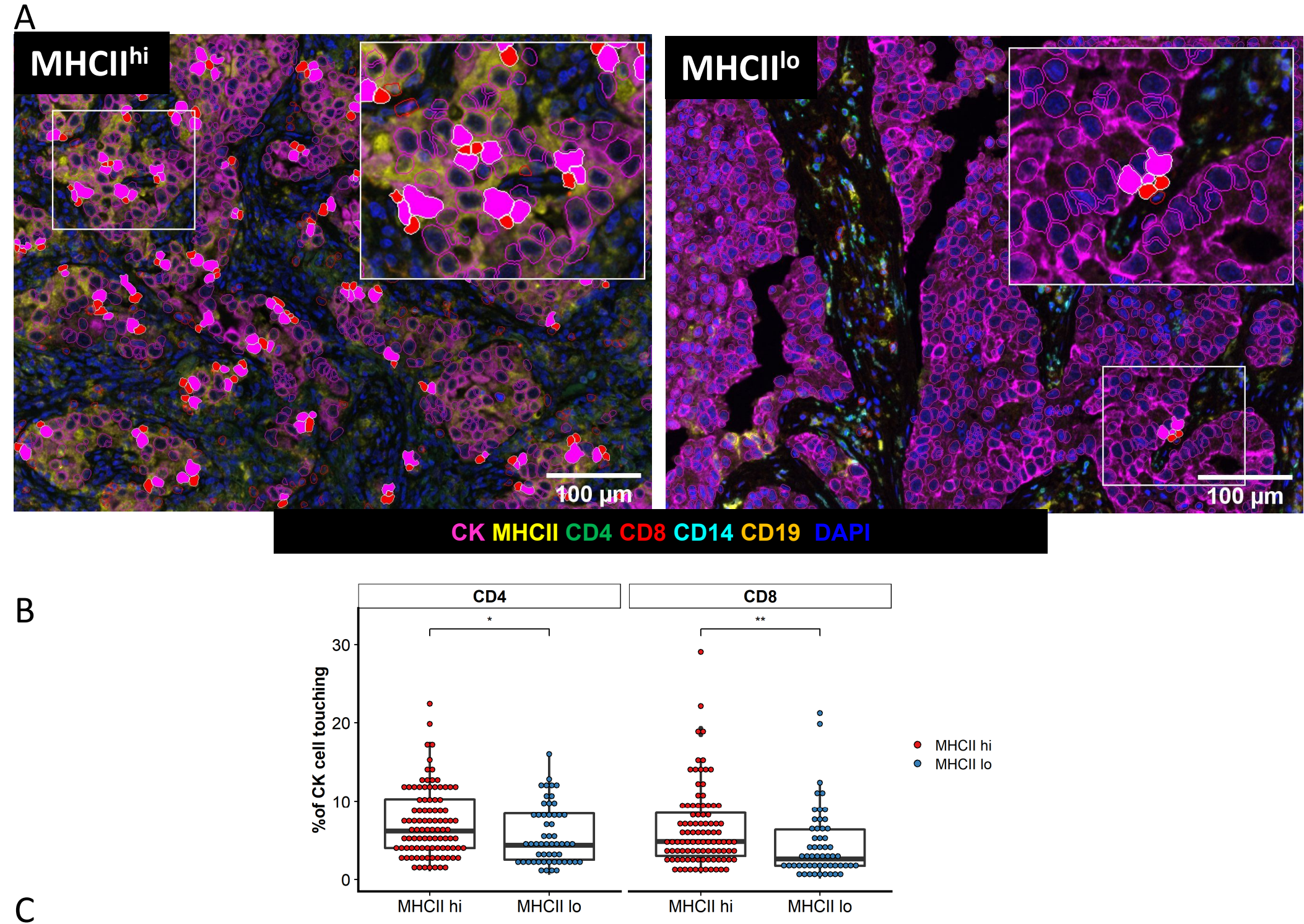

CK MHCII CD4 CD8 CD14 CD19

B

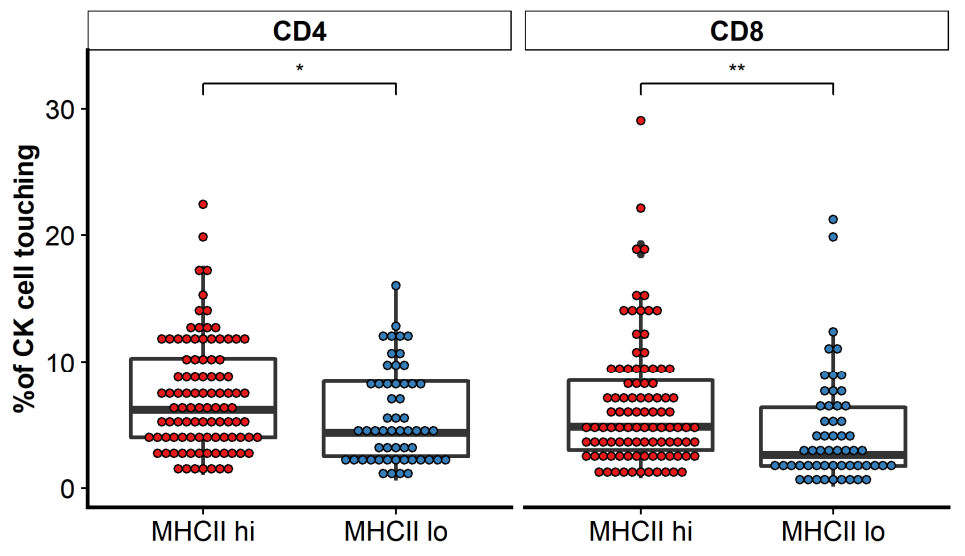

- MHCll hi

- MHCll lo

C
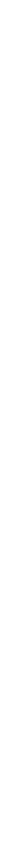
Figure 5

A

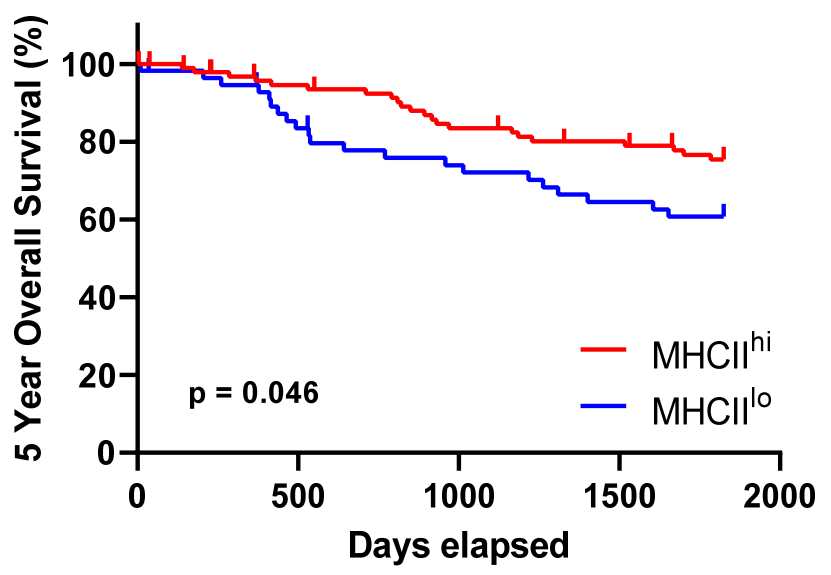

C

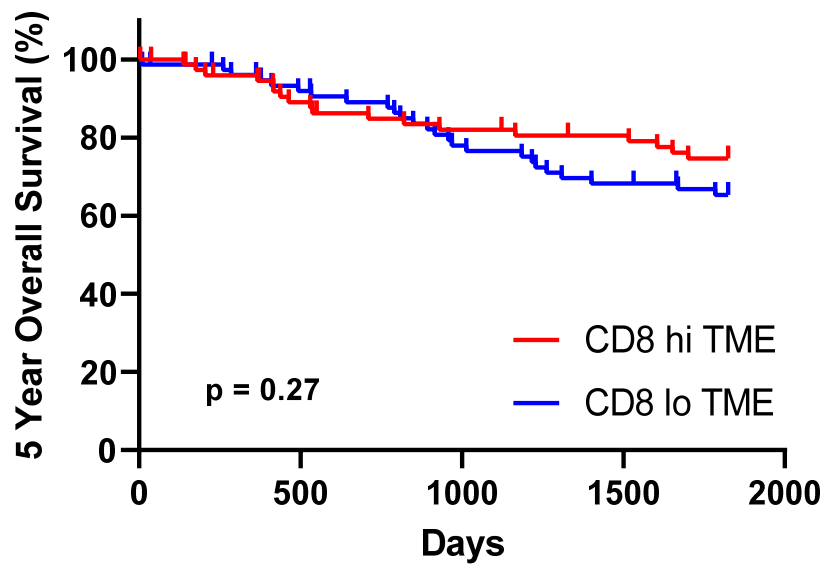

E

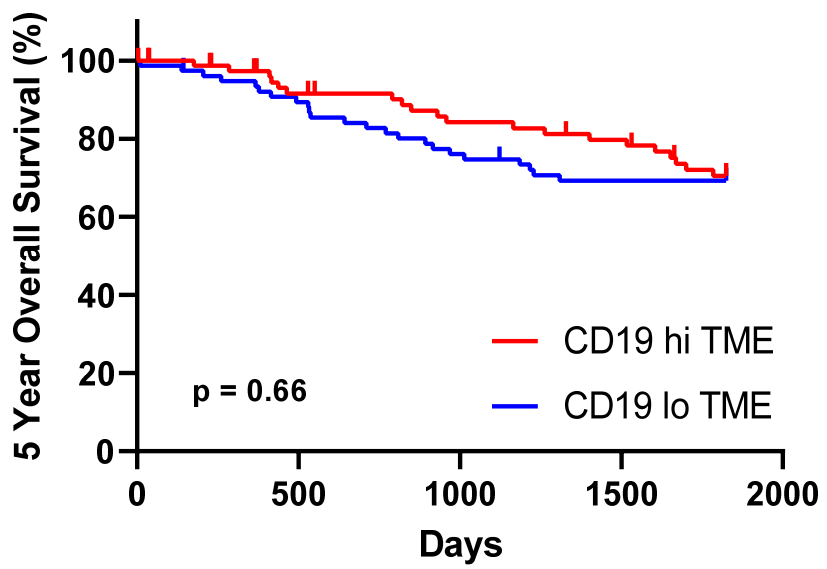

B

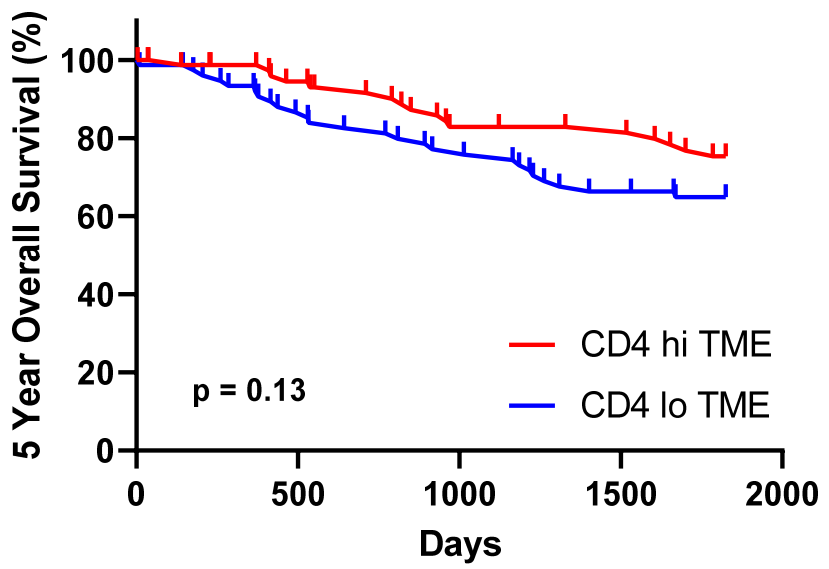

D

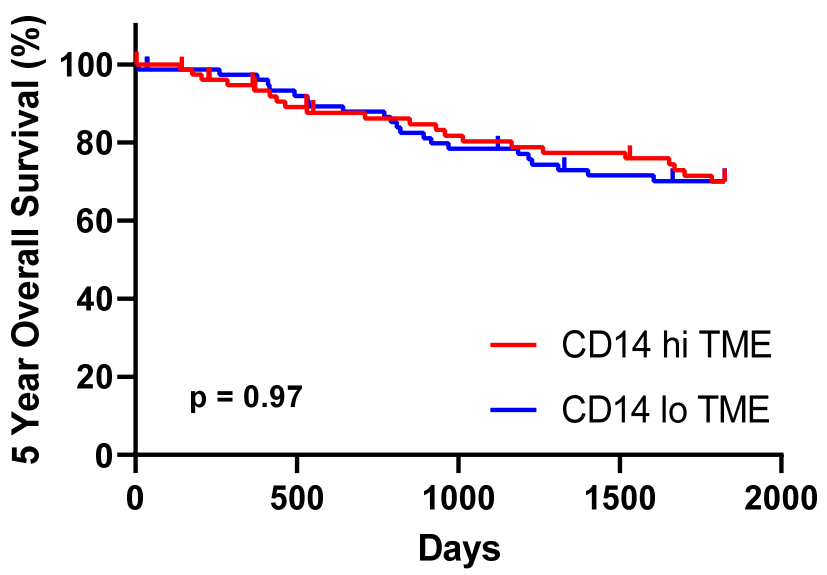


Table 1. Patient characteristics

\begin{tabular}{|c|c|c|}
\hline & $n=153$ & $\%$ \\
\hline \multicolumn{3}{|l|}{ Sex } \\
\hline Male & 72 & 47.1 \\
\hline Female & 81 & 52.9 \\
\hline \multicolumn{3}{|l|}{ Age groups } \\
\hline$<65$ & 50 & 32.7 \\
\hline $65-74$ & 58 & 37.9 \\
\hline$\geq 75$ & 45 & 29.4 \\
\hline \multicolumn{3}{|l|}{ Smoking History } \\
\hline Never & 22 & 14.4 \\
\hline Light Smoker & 10 & 6.5 \\
\hline Heavy Smoker & 112 & 73.2 \\
\hline NA & 9 & 5.9 \\
\hline \multicolumn{3}{|l|}{ Stage (Pathological) } \\
\hline IA & 64 & 41.8 \\
\hline IB & 32 & 20.9 \\
\hline IIA & 16 & 10.5 \\
\hline IIB & 13 & 8.5 \\
\hline IIIA & 21 & 13.7 \\
\hline IIIB & 2 & 1.3 \\
\hline IV & 5 & 3.3 \\
\hline \multicolumn{3}{|l|}{ Stage (Numeric) } \\
\hline 1 & 96 & 62.7 \\
\hline 2 & 29 & 19.0 \\
\hline 3 & 23 & 15.0 \\
\hline 4 & 5 & 3.3 \\
\hline \multicolumn{3}{|l|}{ Cancer Cell MHCII Status } \\
\hline MHC II low < 5\% & 56 & 36.6 \\
\hline MHC II high $\geq 5 \%$ & 97 & 62.7 \\
\hline
\end{tabular}


Table 2. Patient characteristics by cancer cell MHCII status

\begin{tabular}{|c|c|c|c|}
\hline & MHCII'o & MHCIIhi & \\
\hline $\mathbf{n}$ & 56 & 97 & \\
\hline \multicolumn{4}{|l|}{ Sex } \\
\hline Male & 26 & 46 & $p=0.91$ \\
\hline Female & 30 & 51 & \\
\hline \multicolumn{4}{|l|}{ Age groups } \\
\hline$<65$ & 15 & 35 & $p=0.24$ \\
\hline $65-74$ & 26 & 32 & \\
\hline$\geq 75$ & 15 & 30 & \\
\hline \multicolumn{4}{|l|}{ Smoking History } \\
\hline Never & 5 & 17 & $p=0.46$ \\
\hline Light Smoker & 3 & 7 & \\
\hline Heavy Smoker & 44 & 68 & \\
\hline $\mathrm{N} / \mathrm{A}$ & 4 & 5 & \\
\hline \multicolumn{4}{|l|}{ Stage (Pathological) } \\
\hline IA & 25 & 39 & $p=0.2$ \\
\hline IB & 12 & 20 & \\
\hline IIA & 4 & 12 & \\
\hline IIB & 2 & 11 & \\
\hline IIIA & 9 & 12 & \\
\hline IIIB & 2 & 0 & \\
\hline IV & 2 & 3 & \\
\hline \multicolumn{4}{|l|}{ Stage (Numeric) } \\
\hline 1 & 37 & 59 & $p=0.2$ \\
\hline 2 & 6 & 23 & \\
\hline 3 & 11 & 12 & \\
\hline 4 & 2 & 3 & \\
\hline Adjuvant Chemotherapy & & & $p=0.74$ \\
\hline Yes & 7 & 14 & \\
\hline No & 49 & 83 & \\
\hline
\end{tabular}


Table $\mathbf{3}$ Multivariate analysis of $\mathbf{5}$ year overall survival.

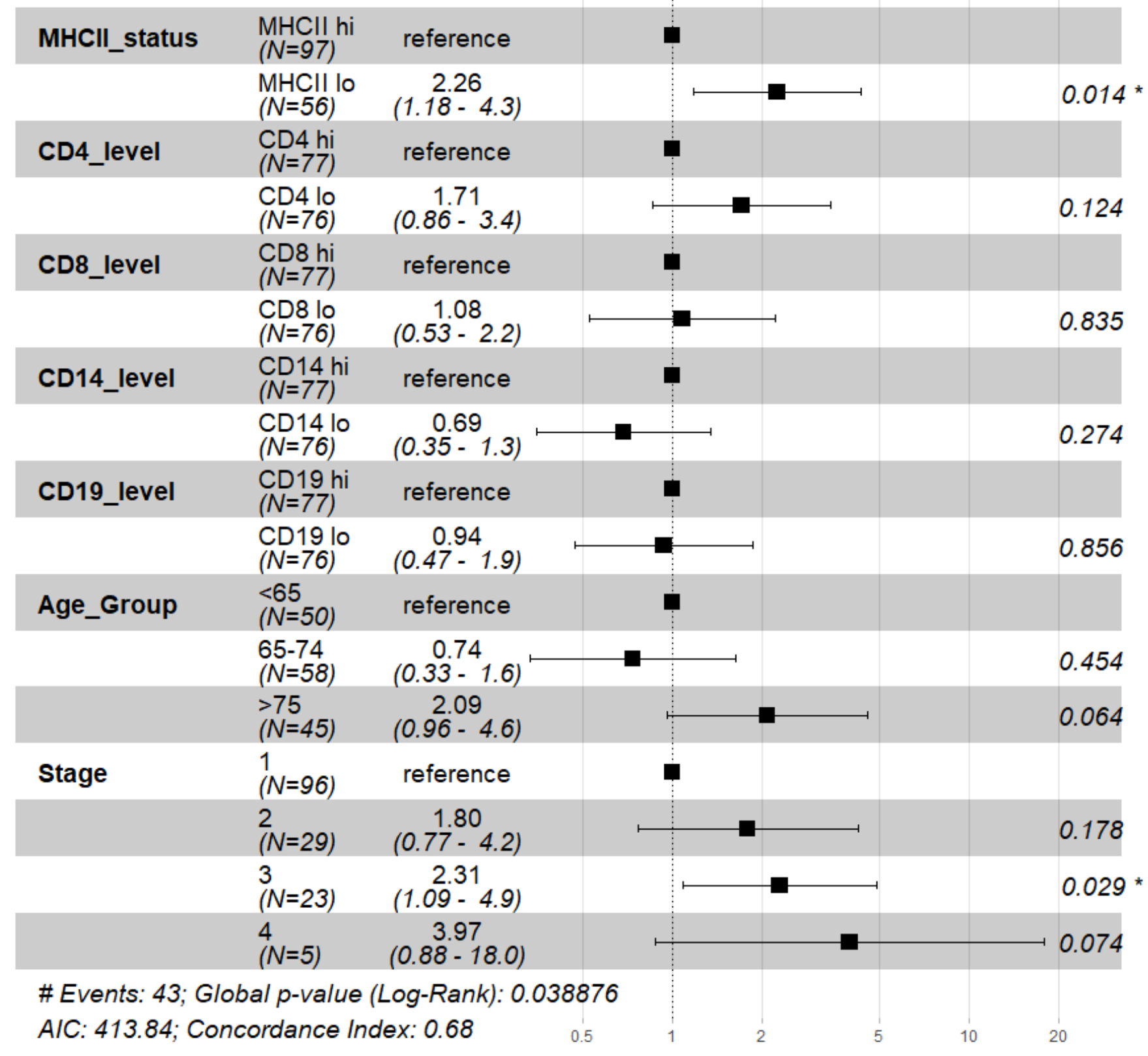


Supplemental Figure 1

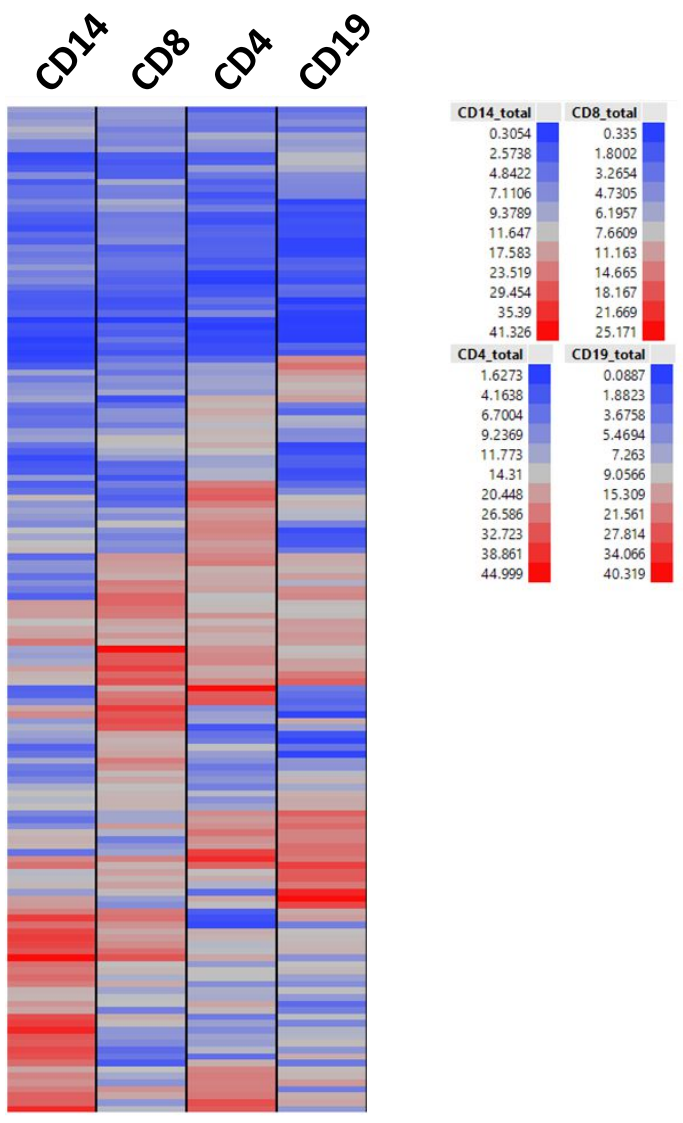


Supplemental Figure 2

A

Tumor Compartment

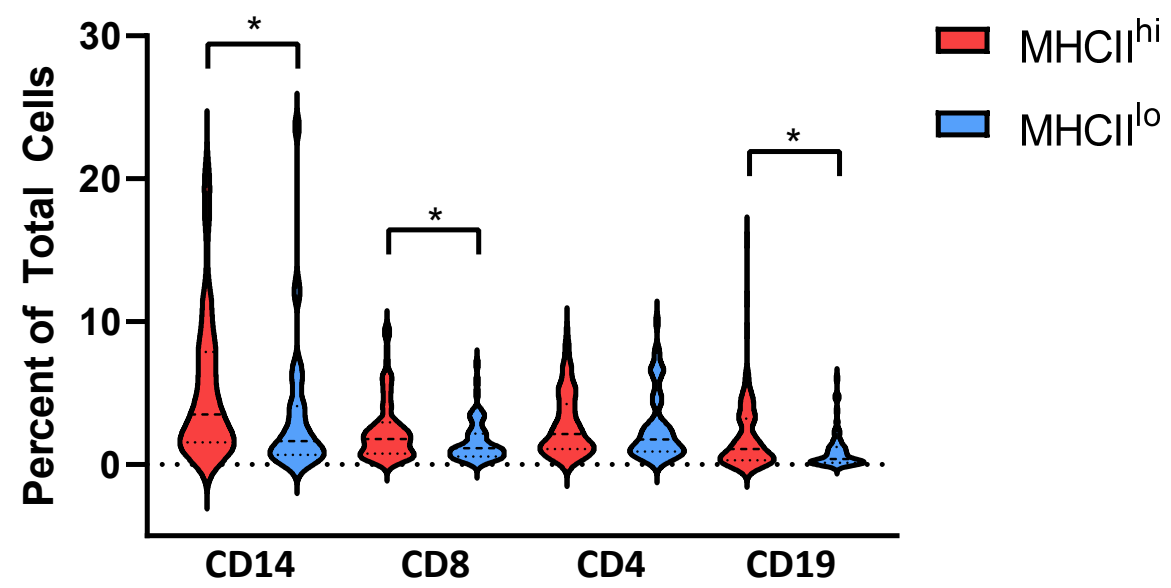

B

Stroma Compartment

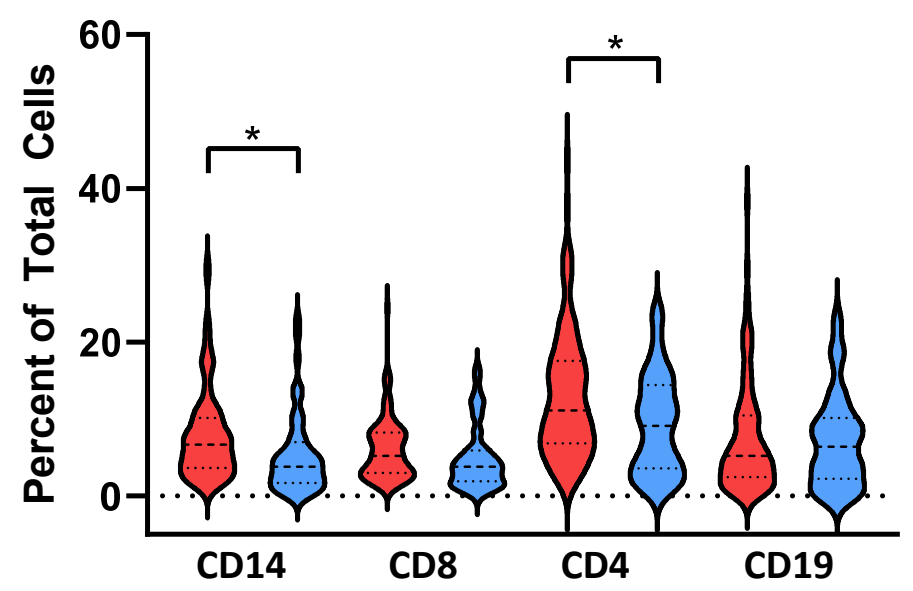




\section{Supplemental Figure 3}

A

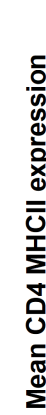

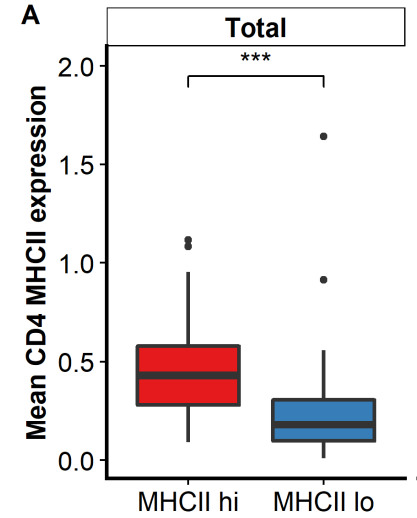

C

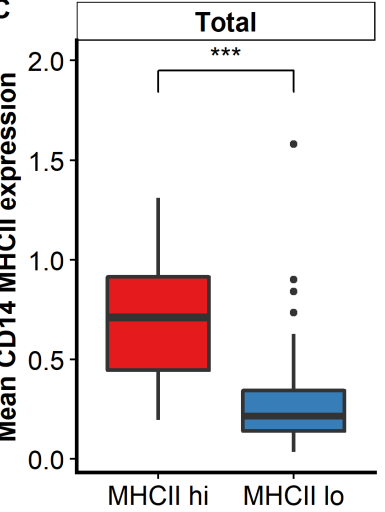

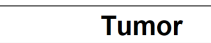

***

Stroma

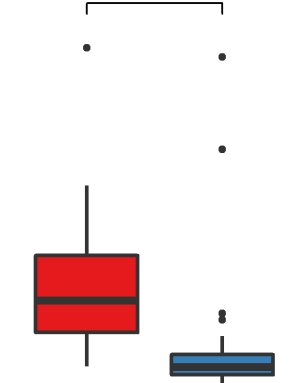

MHCll hi MHCll lo
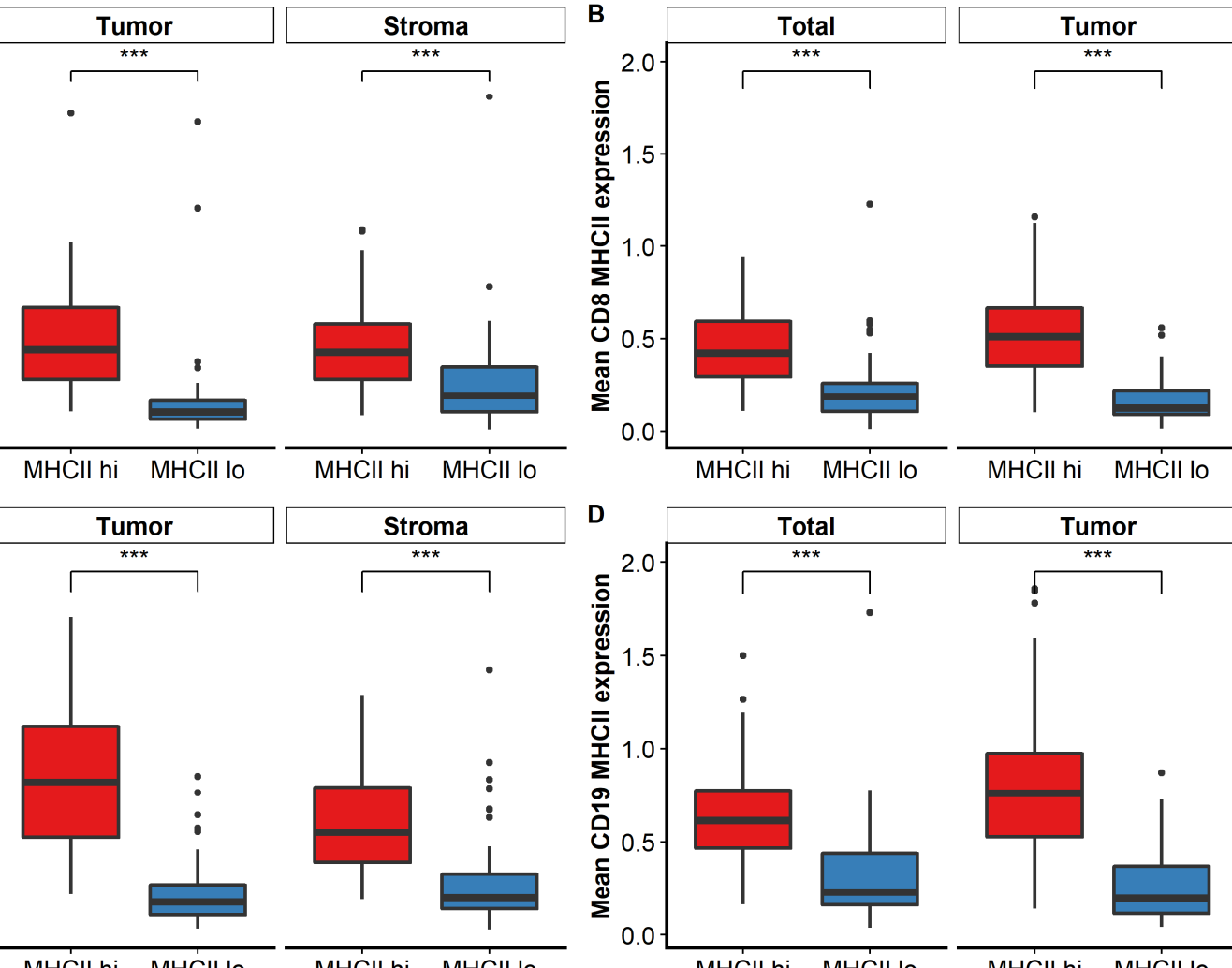

MHCll hi MHCll lo
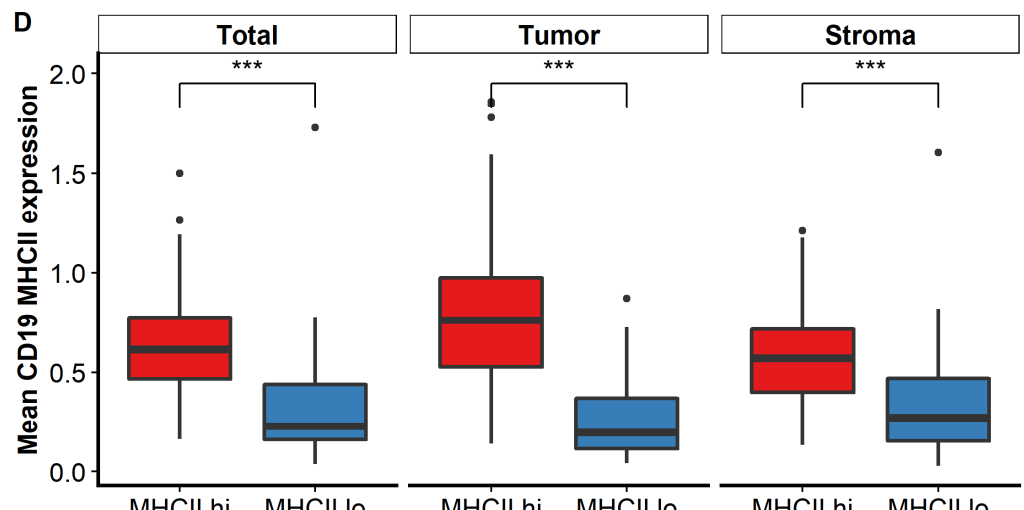


\section{Supplemental Figure 4}
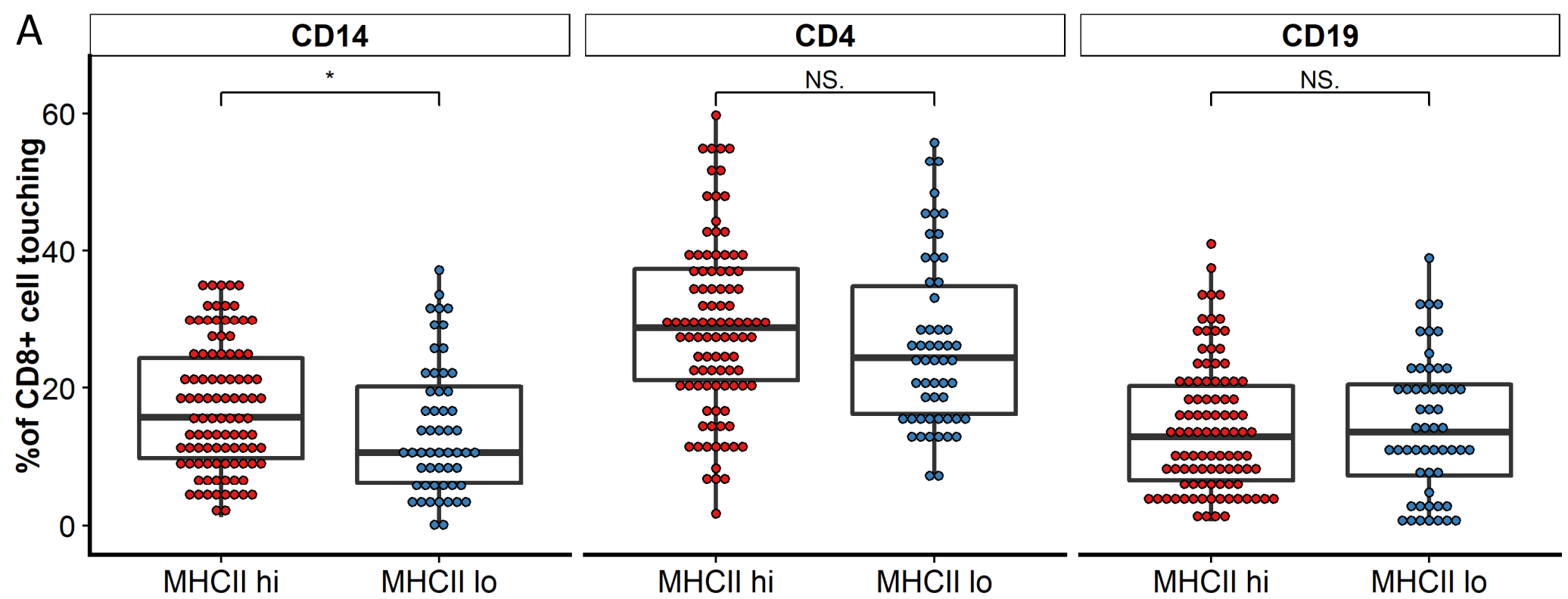

- MHCll hi ○ MHCll lo
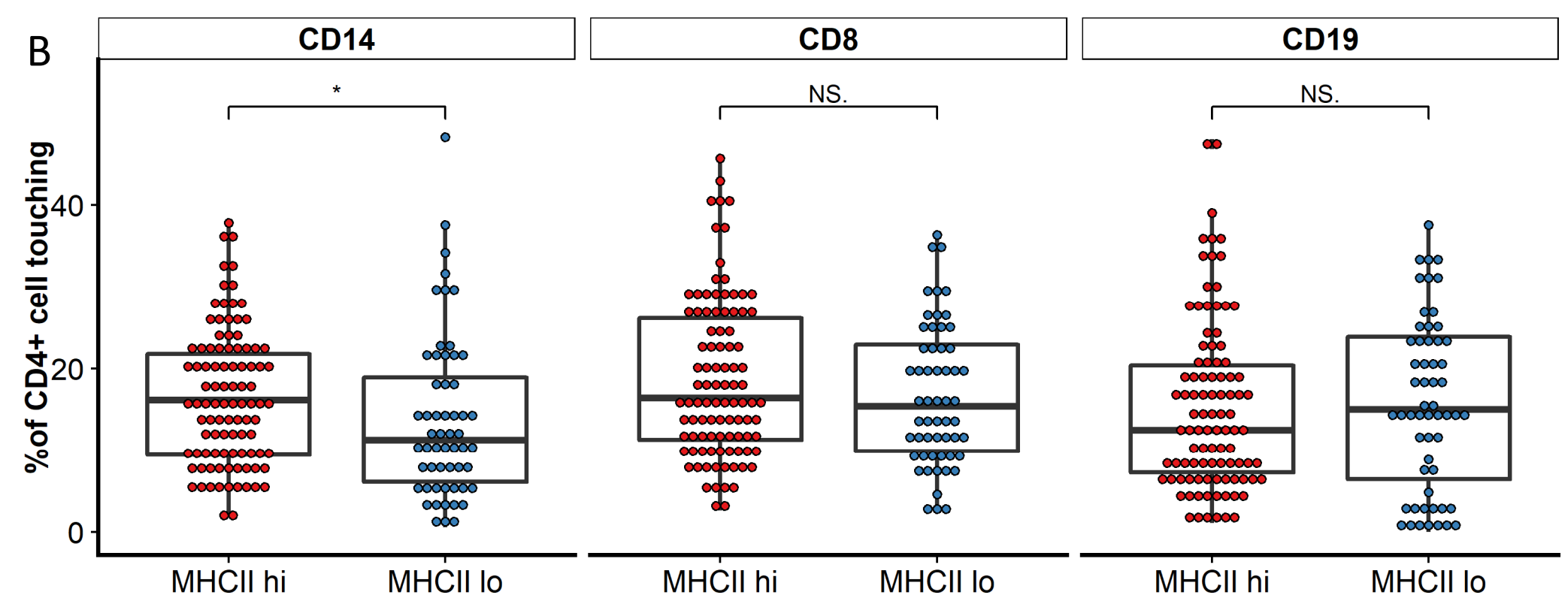